\title{
PENGARUH PERSEPSI PETANI TERHADAP PEMANFAATAN ALSINTAN TRAKTOR TANGAN RODA DUA BERBASIS UPJA DI DESA PANGGUNGHARJO KECAMATAN SEWON KABUPATEN BANTUL DAERAH ISTEMEWA YOGYAKARTA
}

\author{
Arif Nasoi ${ }^{1}$, Adi Prayoga ${ }^{2}$, Asih Farmia ${ }^{2}$ \\ ${ }^{1}$ Mahasiswa Politeknik Pembangunan Pertanian Yogyakarta-Magelang \\ ${ }^{2}$ Dosen Politeknik Pembangunan Pertanian Yogyakarta-Magelang \\ Email: arifemmacpa@gmail.com \\ J1. Kusumanegara No.2, Yogyakarta, 55167
}

\begin{abstract}
This study aims to determine the perception offarmers about the Business Services of Tools and agricultural Machinery (UPJA) and agricultural machinery hand tractors two wheel as well as the influence of the perception of farmers towards utilization of agricultural machinery tractor the two wheel hand based UPJA which was held February 18-June 31, 2019 in Panggungharjo Village, Sub District of Sewon. Method data collection using questionnaire and analysis of documents. Sampling methode used slovin with an error rate $15 \%$. Data was analyzed using simple linear regression.

The results of the study shows the perception of farmers about agricultural machinery and UPJA in the category appropriate to the achievement value of $79.5 \%$, based on the indicator of the attitudes and expectations derived category of right with the achievement of the value of each $79,8 \%$ and $82,7 \%$, interest in the category is very appropriate with the achievement values of $87.5 \%$ and a motive in the category quite right with the achievement score of $68 \%$. The results of the simple linear regression analysis showed a significant influence of the perception of farmers towards utilization of agricultural machinery tractor the two wheel hand based UPJA.
\end{abstract}

Keywords: Perception, the utilization of hand tractor, UPJA

\section{PENDAHULUAN}

Peningkatan produksi dan produktivitas komoditas hasil pertanian merupakan bagian dari strategi untuk meningkatkan pendapatan petani. Program upaya khusus Pajale merupakan program pemerintah untuk meningkatkan produksi padi, jagung dan kedelai. Program ini bertujuan memberikan dukungan prasarana dan sarana pertanian berupa air irigasi, benih, pupuk, alat dan mesin pertanian (alsintan) serta sarana produksi lainnya.

Kabupaten Bantul adalah kabupaten di Daerah Istimewa Yogyakarta, dengan ibukota Bantul. Jarak dari pusat kota Yogyakarta $\pm 12 \mathrm{Km}$, dengan luas wilayah Kabupaten
Bantul adalah 50685 Ha, Traktor roda dua merupakan alat pengolah tanah yang juga digunakan di Daerah Istimewa Yogyakarta dan terbanyak digunakan di Kabupaten Bantul sebesar 39,29\% (BPS DIY, 2017). Banyaknya penggunaan traktor roda dua karena mendukung luas sawah di Kecamatan Sewon, yaitu 1.167 ha (BPS Bantul, 2018).

Peningkatan produksi dan produktivitas komoditas hasil pertanian merupakan bagian dari strategi untuk meningkatkan pendapatan petani. Program upaya khusus Pajale merupakan program pemerintah untuk meningkatkan produksi padi, jagung dan kedelai.Program ini bertujuan memberikan dukungan prasarana dan sarana pertanian 
berupa air irigasi, benih, pupuk, alat dan mesin pertanian (alsintan) serta sarana produksi lainnya

Desa Panggungharjo memiliki luas lahan sawah sebesar 170 Ha (BPS Bantul, 2018) dan merupakan salah satu Desa yang memperoleh bantuan Traktor tangan roda dua dari Pemerintah. Bantuan traktor tangan roda dua diterima oleh 4 kelompok tani masing masing 1 unit dari 7 kelompok tani yang ada di Desa Panggungharjo. Pemanfaatan alat dan mesin pertanian milik kelompok belum memberikan tambahan hasil usaha sesuai harapan anggota kelompok petani. Operasional traktor yang dikelola kelompok tani belum mampu menjangkau secara luas area petani yang ada di wilayahnya dan belum dapat memberikan keuntungan secara signifikan (Hamidah dan Soedarto, 2006).

Traktor tangan roda dua merupakan salah satu alat dan mesin pertanian yang digunakan petani untuk usaha taninya dan dapat dikelola dalam kelembagaan Usaha Pelayanan Jasa Alsintan (UPJA). Namun traktor tangan yang ada di kelompok tani belum dimanfaatkan secara optimal. Hal itu karena terbatasnya pengetahuan teknis petani tentang pemeliharaan alat dan mesin pertanian yang dimiliki kelompok termasuk biaya pemeliharaan alat dan mesin pertanian tersebut, selain itu anggapan petani yang berbeda-beda dalam memanfaatkan alsintan yang dimiliki untuk disewakan dengan berorientasi bisnis dan berorientasi pasar. Padahal, Desa Panggungharjo berpotensi untuk dibentuk UPJA. Hal ini terlihat dari kekurangan jumlah traktor tangan roda dua dibandingkan dengan luas sawah keseluruhan. Berdasarkankondisitersebutperludikaji tentang pengaruh persepsi petani terhadap pemanfaatan alsintan traktor tangan roda dua berbasis UPJA di Desa Panggungharjo Kecamatan Sewon, Kabupaten Bantul.

Kajian ini bertujuan untuk mengetahui persepsi petani tentang alsintan traktor tangan roda dua dan UPJA serta pengaruh persepsi petani terhadap pemanfaatan alsintan traktor tangan roda dua berbasis UPJA.

Persepsi merupakan pengorganisasian, penginterpretasian terhadap stimulus yang diinderanya sehingga merupakan sesuatu yang berarti, dan merupakan respon yang integrated dalam individu (Walgito, 2003). Menurut Ruch (1967:300), dalam Hadiwijaya (2011) persepsi adalah suatu proses tentang petunjuk inderawi (sensory) dan pengalaman masa lampau yang relevan diorganisasikan untuk memberikan kepada kita gambaran yang berstruktur dan bermakna pada suatu situasi tertentu. Dari beberapa pengertian tersebut dapat digarisbawahi bahwa persepsi merupakan suatu proses yang dimulai dari penglihatan hingga terbentuk tanggapan yang terjadi dalam diri individu sehingga individu sadar akan segala sesuatu dalam lingkungannya melalui indera-indera yang dimilikinya.

Pada dasarnya, persepsi tidak ditentukan oleh jenis bentuk stimuli, tetapi bergantung pada karakteristik orang yang memberikan respons terhadap stimuli tersebut (Alex Sobur, 2003:461) Apa yang kita hayati tidak hanya bergantung pada stimulus, tetapi juga pada proses kognitif yang merefleksikan minat, tujuan, dan harapan seseorang pada saat itu. Pemusatan persepsi ini disebut "perhatian". Perhatian mempunyai fungsi memiliki dan mengarahkan rangsangan-rangsangan yang 
sampai kepada kita, sehingga tidak kita terima secara kacau. Perhatian dipengaruhi oleh beberapa faktor yang dapat dibagi dalam dua golongan besar, yaitu faktor luar dan faktor dalam. Faktor luar adalah faktor-faktor yang terdapat pada objek yang diamati itu sendiri, yaitu intensitas atau ukuran, kontras, pengulangan, dan gerakan; sedangkan faktor dalam adalah faktor-faktor yang berasal dari dalam diri individu si pengamat, yaitu motif, kesediaan, dan harapan (Dirgagunarsa, 1996:107) dalam Alex Sobur (2003)

Untukmengukurpersepsimenggunakan indikator, diantaranya adalah sikap, motif, kepentingan, dan pengharapan (Setyati dan Dwiatmaja, 2014). Hipotesis yang diajukan dalam kajian ini adalah diduga persepsi petani berpengaruh terhadap Pemanfaatan Alsintan traktor tangan berbasis UPJA.

\section{METODOLOGI}

Kajian ini dilaksanakan di Desa Panggungharjo, Kecamatan Sewon, Kabupaten Bantul, DI Yogyakarta, dimulai pada 18 Februari 2019 sampai dengan 30 Juni 2019. Pemilihan lokasi dilakukan secara purposive. Karakteristik populasi dari kajian ini adalah 4 Kelompok Tani yang telah menerima bantuan traktor tangan roda dua dari pemerintah. Penentuan sampel petani untuk kajian ditentukan dengan rumus Slovin (Sevilla et. al., 1960:182) dalam Didik et al (2015):

$$
\mathbf{n}=\frac{\mathbf{N}}{1+\mathbf{N e}^{2}}
$$

Keterangan:

$$
\begin{aligned}
& \mathrm{n}=\text { ukuran sampel } \\
& \mathrm{N}=\text { jumlah populasi yaitu } 424 \\
& \mathrm{e}=\text { margin of error } 0,15
\end{aligned}
$$

Sehingga jumlah sampel yang diperoleh adalah 40 orang dengan perhitungan sebagai berikut:

$$
\begin{aligned}
\mathrm{n} & =\frac{424}{1+424 \cdot(0,15)^{2}}=\frac{424}{1+424 \cdot 0,0225}=\frac{424}{1+9,54} \\
& =\frac{424}{10,54}=40,2=40 \text { orang }
\end{aligned}
$$

Data yang digunakan dalam kajian ini adalah data primer dan data sekunder. Data primer diperoleh langsung dari responden melalui kuesioner yang telah disusun, sedangkan data sekunder diperoleh dari BPP Sewon. Metode pengumpulan data dalam kajian ini dilakukan dengan cara obeservasi, wawancara, kusioner, dan dokumentasi. Skala pengukuran dalam kajian ini adalah skala ordinal dengan 5 (lima) kategori untuk persepsi traktor tangan dan UPJA yang ditranformasikan ke interval dengan interval kelas 16, sehingga didapat 5 (lima) range skor dan untuk persepsi pemanfaatan traktor tangan roda dua adalah skala ordinal dengan 3 (tiga) kategori dengan interval kelas 22,2, sehingga didapat 3 (tiga) range skor.

Analisis data dalam kajian ini dilakukan dengan teknik analisis deskriptif untuk mendeskripsikan data yang diperoleh dan analisis regresi sederhana untuk mengetahui pengaruh antara variabel independen dan variabel dependen. Pengambilan keputusan uji pengaruh berdasarkan kriteria sebagai berikut :

- Jika nilai $\mathrm{t}$ hitung $>\mathrm{t}$ tabel $(0,05)$, maka ada pengaruh antara variabel $\mathrm{X}$ terhadap variabel Y.

- Jika nilai $\mathrm{t}$ hitung $<\mathrm{t}$ tabel $(0,05)$, maka tidak ada pengaruh variabel $\mathrm{X}$ terhadap variabel Y.

Persamaan regresi linear sederhana dengan model sebagai berikut :

$$
\mathbf{Y}=\mathbf{a}+\mathbf{b X}
$$


Dimana :

$$
\begin{aligned}
\mathrm{Y}= & \text { Pemanfaatan Alsintan traktor tangan } \\
& \text { roda dua berbasis UPJA } \\
\mathrm{a}= & \text { Kostanta } \\
\mathrm{X}= & \text { Persepsi } \\
\mathrm{b}= & \text { Koefisien Regresi }
\end{aligned}
$$

\section{HASIL DAN PEMBAHASAN}

\section{Keadaan Wilayah dan Penduduk}

Luas wilayah Desa Panggungharjo adalah 561 ha yang penggunaannya terdiri dari luas lahan sawah 170 ha, lahan pertanian bukan sawah 8 ha, dan lahannon pertanian 383 ha (BPS, 2018). Lahan yang dimanfaatkan untuk sektor pertanian, yaitu berupa sawah sebesar 30,3\% dari luas wilayah Desa Panggungharjo. Kondisi ini menunjukkan bahwa Desa Panggungharjo mempunyai potensi pertanian yang cukup besar. Desa Panggungharjo memiliki penduduk sebanyak 35.160 jiwa yang terdiri dari 18.230 laki-laki dan 17.930 perempuan (BPS, 2018).

Menurut BP3K Sewon (2019) mata pencaharian penduduk Desa Panggungharjo dengan mata pencaharian di sektor pertanian menyumbang prosentase $46,6 \%$ yang terdiri dari petani pemilik, petani pemilik penggarap, petani penggarap, petani penyewa dan buruh tani.

\section{Karakteristik Responden}

Karekteritik dari masing-masing petani tidaklah sama yang dapat mempengaruhi persepsi petani terhadap pemanfaatan traktor tangan roda dua. Karekteristik petani yang

\begin{tabular}{|c|c|c|c|}
\hline No & Umur & $\begin{array}{l}\text { Jumlah responden } \\
\text { (orang) }\end{array}$ & Persentase $(\%)$ \\
\hline 1 & $0-14$ & 0 & 0 \\
\hline 2 & $15-64$ & 30 & 75 \\
\hline 3 & $65-76$ & 10 & 25 \\
\hline & Jumlah & 40 & 100 \\
\hline
\end{tabular}
penting diketahui dalam kajian ini adalah umur,pendidikan dan luas lahan
Tabel 1. Karakteristik Responden Menurut Umur

Tabel 1 mengindikasikan bahwa dari segi umur petani sebagian besar berumur produktif sehingga dimungkinkan masih mampu dalam mengelola dan mengoperasikan traktor tangan roda dua di dalam kelembagaan UPJA.

Tabel 2. Karakteristik Responden Menurut Tingkat Pendidikan

\begin{tabular}{llll}
\hline No & $\begin{array}{c}\text { Tingkat } \\
\text { Pendidikan }\end{array}$ & $\begin{array}{c}\text { Jumlah Responden } \\
\text { (orang) }\end{array}$ & $\begin{array}{c}\text { Persentase } \\
(\%)\end{array}$ \\
\hline 1 & Tidak Sekolah & 1 & 2,5 \\
2 & SD & 8 & 20 \\
3 & SLTP & 10 & 25 \\
4 & SLTA & 20 & 50 \\
& Perguruan Tinggi & 1 & 2,5 \\
\hline \multicolumn{5}{l}{ Jumlah } & 40 & 100 \\
\hline \multicolumn{2}{l}{ Sumber: Olahan data primer, 2019 }
\end{tabular}

Tabel 2 menunjukkan bahwa responden dengan kriteria tingkat pendidikan dasar/ rendah (hingga tamat SLTP) sebanyak 19 orang (47,5\%), tamat pendidikan menengah

\begin{tabular}{|c|c|c|c|}
\hline No & $\begin{array}{l}\text { Klasifikasi luas } \\
\text { lahan sawah (ha) }\end{array}$ & $\begin{array}{c}\text { Jumlah responden } \\
\text { (orang) }\end{array}$ & $\begin{array}{c}\text { Persentase } \\
\quad(\%)\end{array}$ \\
\hline 1 & $<0,5$ & 32 & 80 \\
\hline 2 & $0,5-1$ & 8 & 20 \\
\hline & Jumlah & 41 & 100 \\
\hline
\end{tabular}
atas sebanyak 20 orang $(50 \%)$, tamat pendidikan tinggi sebanyak 1 orang $(2,5 \%)$.

Tabel 3. Karakteristik Petani Menurut Kepemilikan Lahan Sawah

Tabel 3 menunjukkan bahwa sebagian petani responden sebanyak 32 orang atau $80 \%$ mempunyai luas lahan garapan $<0,5$ ha sedangkan 8 orang atau $20 \%$ mempunyai lahan garapan 0,5 - 1 ha. Hal ini menunjukkan 
bahwa kegiatan pertanian di wilayah tersebut, rata-rata dilakukan oleh petani dengan luas lahan yang sempit, sehingga berpengaruh pada skala usahatani yang dilakukan menjadi kecil dan mempengaruhi pendapatan petani.

\section{Analisa Deskriptif Persepsi}

Persepsi dalam kajian ini adalah tentang pemanfaatan traktor tangan dan UPJA. Terdapat empat indikator yang digunakan untuk mengukur persepsi petani, antara lain sikap, motif, kepentingan, dan harapan. Tingkat persepsi petani terhadap pemanfaatan alsintan traktor tangan dalam kelembagaan UPJA termasuk dalam kategori tepat dengan nilai capaian rata - rata 79,5\%. Hasil analisis deskriptif persepsi petani ditunjukkan pada tabel 4.

Tabel 4. Capaian Masing-Masing Indikator Persepsi

\begin{tabular}{|c|c|c|c|}
\hline No & Indikator & Capaian (\%) & Kategori \\
\hline 1 & Sikap & 79,8 & Tepat \\
\hline 2 & Motif & 68,0 & Cukup Tepat \\
\hline 3 & Kepentingan & 87,5 & Sangat Tepat \\
\hline \multirow[t]{2}{*}{4} & Harapan & 82,7 & Tepat \\
\hline & Rata-Rata & 79,5 & Tepat \\
\hline
\end{tabular}

Sumber: Olahan data primer, 2019

Persepsi petani terhadap pemanfaatan traktor tangan berbasis UPJA merupakan penilaian petani yang dicerminkan pada pandangannya, persepsi anggota petani tentang pemanfaatan traktor tangan dalam kategori tepat namun belum membentuk kelembagaan UPJA. Walaupun Permentan Nomor 25 Tahun 2008 tentang pedoman penumbuhan dan pengembangan UPJA sudah sejak lama berlaku, tetapi petani di Desa Panggungharjo belum membentuk UPJA dalam rangka peningkatan pemanfaatan alsintan traktor tangan roda dua. UPJA belum adanya karena penyuluhan tentang
UPJA belum optimal, maka wajar jika petani menganggap mereka belum mampu untuk membentuknya.

\section{Sikap}

Berdasarkan hasil kajian persepsi petani terkait dengan sikap petani dalam pemanfaatan alsintan traktor tangan berbasis UPJA rata-rata dalam kategori tepat dengan nilai 79,8\%. Petani mempersepsikan dirinya mengetahui tentang pemanfaatan traktor tangan dalam kegiatan usaha taninya bahwa traktor tangan lebih efektif dan efisien dibanding pengolahan lahan secara tradisonal. Tingginya pengetahuan petani dapat disebabkan oleh salah satunya adalah pendidikan, petani rata-rata tamatan SLTA, semakin tinggi tingkat pendidikan atau semakin lama seseorang mengenyam pendidikan akan semakin rasional pola pikir dan penalarannya. Hal ini sesuai dengan pendapat Slamet (2003) dalam Ningtyas et al (2017) pendidikan merupakan suatu faktor penting bagi kehidupan manusia. Pendidikan merupakan proses pembentukan pribadi seseorang. Melalui pendidikan seseorang akan memperoleh pengetahuan, sikap dan keterampilan baru. Tingkat pendidikan akan mempengaruhi nilai-nilai yang dianutnya, cara berfikir, cara pandang bahkan persepsinya terhadap suatu masalah.

\section{Motif}

Persepsi petani terkait dengan motifnya dalam pemanfaatan alsintan traktor tangan berbasis UPJA dengan hasil nilai $68 \%$ termasuk kategori cukup tepat. Hasil temuan di lapangan motif petani enggan untuk ikut terlibat dalam kelembagaan UPJA karena mereka beranggapan bahwa hal tersebut merupakan kewajiban pengurus kelompok. 
Petani menganggap umur mereka sudah tua dengan rata-rata umur 59 tahun sehingga itu merupakan kewajiban bagi mereka yang berumur masih muda, pada umumnya petani yang berumur muda mempunyai kemampuan fisik yang lebih kuat serta relatif lebih mudah memerima informasi teknologi dibanding dengan petani yang berumur lebih tua. Hal tersebut sesuai dengan pernyataan Soekartawi dalam Aprilia et al (2018) jika Petani yang berumur lebih muda biasanya akan lebih bersemangat dalam melakukan usaha tani dari pada petani yang berumur tua. Petani biasanya hanya menjadi pihak yang memperoleh jasa, sedangkan pihak yang berhubungan langsung dengan alsintan yang dikelola kelompok tani hanya operator, ketua, dan bendahara.

\section{Kepentingan}

Hasil olah data persepsi petani berdasar indikator kepentingan termasuk ketegori tertinggi dengan nilai $87,5 \%$ dan termasuk dalam kategori sangat tepat. Petani merasa bahwa penting untuk memanfaatkan dan mengelola alsintan traktor tangan dalam kelembagaan UPJA sehingga. Petani beranggapan bahwa dengan pembentukan UPJA dapat meningkatkan pemanfaatan fungsi traktor tangan karena dapat mempermudah pelayanan jasa penyewaan. Sehingga akses petani yang mudah dalam pemanfaatan traktor tangan akan dapat memenuhi kebutuhanya untuk pengolahan tanah dalam usahatani nya sejalan dengan hasil kajian Setyati dan Dwiatmaja (2010) Persepsi seseorang terhadap pekerjaannya, biasanya didasari sejauh mana pekerjaan itu dapat memenuhi kebutuhan dan kepentingan pribadinya, termasuk kebutuhan untuk mengembangkan potensi dan kemampuan diri.

\section{Harapan}

Temuan lapangan menunjukan nilai dari persepsi petani berdasar indikator harapan dalam kategori tepat dengan nilai $82,7 \%$. Petani memiliki harapan yang tinggi nantinya UPJA dapat mendukung kelancaran usahatani khususnya penggunaaan traktor tangan dalam pengolahan tanah, Petani telah mengetahui bahwa adanya traktor tangan sangat membantu kelancaran usaha tani.

Persepsi petani tentang UPJA harus disempurnakan dengan cara memberikan informasi melalui penyuluhan dan pelatihan tentang UPJA kepada petani serta manfaatnya untuk pengoptimalan pemanfaatan fungsi alsintan sehingga petani mengerahkan kemampuan yang dimiliki untuk mencapai harapan yang diinginkan. Sejalan dengan pernyataan Snyder (2002) dalam Permatasari (2017) Harapan merupakan keseluruhan dari kemampuan yang dimiliki individu untuk menghasilkan jalur mencapai tujuan yang diinginkan, bersamaan dengan motivasi yang dimiliki untuk menggunakan jalur-jalur tersebut.

\section{Uji Hipotesa}

Berdasarkan hasil analisis regresi linear sederhana menggunakan SPSS diperoleh hasil bahwa variabel (X) Persepsi petani berpengaruh terhadap variabel pemanfaatan alsintan traktor tangan roda dua berbasis UPJA, sebagaimana ditunjukan pada tabel 5.

Dari tabel 5 dapat dilihat bahwa hasil perhitungan uji thitung 5,283 > t tabel 2,021 pada taraf signifikansi $5 \%$ yang berarti bahwa Ha diterima. Selain itu juga diperoleh persamaan regresi $\hat{Y}=-2,720+0,073 X$. 
Nilai koefisien variabel persepsi sebesar 0,073 artinya setiap penambahan 1 satuan persepsi akan meningkatkan pemanfaatan traktor tangan berbasis UPJA (Y) sebesar
0,073 satuan. Semakin tinggi persepsi maka semakin tinggi juga kognisi petani mengenai pemanfaatan alsintan traktor tangan roda dua.

Tabel 5. Persepsi petani terhadap variabel pemanfaatan alsintan traktor tangan roda dua berbasis UPJA

Coefficients $^{\mathrm{a}}$

\begin{tabular}{|c|c|c|c|c|c|c|}
\hline Model & \multicolumn{2}{|c|}{ Unstandardized Coefficients } & \multirow{2}{*}{\multicolumn{2}{|c|}{$\frac{\text { Standardized Coefficients }}{\text { Beta }}$}} & $\mathrm{t}$ & \multirow[t]{2}{*}{ Sig. } \\
\hline & $\mathrm{B}$ & Std. Error & & & & \\
\hline (Constant) & & -2.720 & .811 & & -3.355 & .002 \\
\hline Persepsi & & .073 & .014 & .651 & 5.283 & .000005 \\
\hline
\end{tabular}

dependent variable: pemanfaatan traktor tangan roda dua berbasis UPJA

Sumber: Output data SPSS, 2019

Petani yang mempunyai ketepatan persepsi tentang pemanfaatan traktor tangan roda dua berbasis UPJA akan cenderung selalu menggunakan traktor dalam setiap usaha taninya dan berminat untuk mengelola alsintan dalam kelembagaan UPJA selaras dengan pendapat Gibson dalam Saribekti (2012) persepsi meliputi juga kognisi (pengetahuan), yang mencakup penafsiran objek, tanda dan orang dari sudut pengalaman yang bersangkutan. Pernyataan tersebut didukung oleh De vito dalam Krisnawati (2013) faktor-faktor yang mempengaruhi ketepatan persepsi adalah umur, kecerdasan, kompleksitas, kognitif, popularitas, ciri-ciri pribadi, dan kesan latihan atau hasil belajar. Hal tersebut karena tingkat Pendidikan petani responden adalah sebagian besar adalah SLTA sehingga semakin tinggi tingkat pendidikan maka semakin baik petani menilai pemanfaatan traktor tangan berbasis UPJA hal ini sesuai dengan pendapat Arumbawa dalam Krisnawati (2013) pendidikan formal merupakan salah satu faktor interen yang mempengaruhi persepsi, pendidikan formal berkaitan erat dengan kognitif seseorang dalam menafsirkan situasi yang dirasakannya dan memahami informasi.

\section{KESIMPULAN DAN SARAN}

Kesimpulan

1. Persepsi petani terhadap pemanfaatan alsintan traktor tangan roda dua berbasis UPJA dalam kategori tepat yaitu dengan capaian $78,65 \%$.

2. Persepsi berpengaruh terhadap pemanfaatan traktor tangan roda dua berbasis UPJA.

Saran

1. Perlunya membangun persepsi petani melalui peningkatan baik sikap, motif, kepentingan dan harapan melalui penyuluhan tentang kelembagaan UPJA untuk mengelola alsintan traktor tangan roda dua agar pemanfaatan traktor lebih optimal.

2. Perlunya penumbuhan UPJA sebagai wadah untuk mengelola alsintan traktor tangan roda dua.

\section{DAFTAR PUSTAKA}

Alex, Sobur. 2003. Psikologi Umum. Bandung: Pustaka Setia 
Aprilia. E, Andriani. R,Kusumo B. 2018. Motivasi Petani Dalam Mewujudkan Ketahanan Pangan Rumah Tangga Petani Padi Sawah Di Desa Jatiragas Hilir, Kecamatan Patok Besi, Kabupaten Subang Jurnal Agroinfo Galuh Volume4 Nomor 3, Mei 2018

BP3K Sewon. 2019 Programa BP3K Sewon

BPS Bantul. 2017. Bantul dalam Angka 2017. BPS Bantul. Yogyakarta. BPS Bantul. 2018. Bantul dalam Angka 2018. BPS Bantul. Yogyakarta.

Didik, M. Wahyudi R. 2015 Analisis Pemanfaatan Infrastrukur Teknologi Informasi Untuk Mendukung Program E-Government Pada Kantor Kementerian Agama Di Wilayah Provinsi Di Yogyakarta. Jurnal Kaunia Vol. XI No. 2, UIN

Hadiwijaya,H. 2011 Persepsi Siswa Terhadap Pelayanan Jasa Pendidikan Pada Lembaga Pendidikan El Rahma Palembang. Jurnal, Nomor 3 September hlm 221-237.

Hamidah dan Soedarto, T. 2006. Analisis Operasional Traktor Tangan pada Usaha Pelayanan Jasa Alsintan Pola Kerjasama Operasional di Kabupaten Gresik. Jurnal Ilmu-Ilmu Ekonomi, Vol.6 No.2 September 2006.

Kementrian Pertanian. 2008. Peraturan Menteri Pertanian Nomor 25/ Permentan/P1.130/5/2008 tentang Pedoman Penumbuhan dan
Pengembangan Usaha Pelayanan Jasa Alat dan Mesin Pertanian. Jakarta.

Krisnawati. 2013. Persepsi Petani Terhadap Peranan Penyuluh Pertanian Di Desa Sidomulyo Dan Muari Distrik Oransbari Kabupaten Manokwari Selatan. Jurnal Sosio Konsepsia Vol. 3, No. 01 Kementerian Sosial Republik Indonesia

Ningtyas T, Dita Wahyu. 2017. Persepsi Konsumen Terhadap Media Pemasaran Online (Kasus Media Pemasaran www.goodplant.co.id). thesis, Universitas Sebelas Maret.

Permatasari,D. 2017. Hubungan Dukungan Orangtua dan Harga Diri dengan Harapan sebagai Variabel Mediator. Jurnal Psikodimensia Volume 16 Nomor 1 2017, Universitas Muhammadiyah Malang

Saribekti R. 2012. Hubungan antara persepsi terhadap insentif dengan kepuasan kerja karyawan, Skripsi Universitas Muhammadiyah Surakarta

Setyati dan Dwiatmaja, C. 2014. Analisis Pengaruh Persepsi Diri, Motivasi, dan Konsep Diri terhadap Kinerja Guru Near Phase Pension di SMA Negeri 1 Semarang. Jurnal Riset Ekonomi dan Bisnis, Vol.7 No.1.

Walgito, B. 2003. Psikologi Sosial (Suatu Pengantar). Penerbit Andi Offset. Yogyakarta. 